\title{
SOLUÇÃO DE CONFLITOS NA UNIÃO EUROPÉIA: LIÇÕES PARA O MERCOSUL?
}

\author{
Umberto Celli Jinior \\ Professor Doutor de Direito Internacional da Faculdade de \\ Direito da Universidade de São Paulo. "Master of Philosophy" \\ em Direito Internacional pela Faculdade de Direito da \\ Universidade de Nottingham, Inglaterra.
}

\section{Resumo:}

A prática tem demonstrado que a evolução do processo de integração da União Européia deve-se, em larga medida, à existência do controle jurisdicional supranacional exercido pelo Tribunal de Justiça, a Corte de Luxemburgo. Alguns sustentam, inclusive, que certas decisões proferidas pelo Tribunal podem ser qualificadas como uma "verdadeira e pacífica revolução judicial". O objetivo deste artigo é o de demonstrar como, por meio de algumas decisões históricas, o Tribunal de Justiça abriu caminho para passar a exercer efetivamente o controle jurisdicional da Comunidade, conferindo eficácia a seu ordenamento jurídico e assegurando, conseqüientemente, a consolidação do processo de integração. Ademais, algumas ponderações são feitas acerca da adequação desse sistema de solução de controvérsias ao Mercosul.

\begin{abstract}
:
One may contend that, from a practical point of view, the development of the European Union integration process is duc, to a large extent, to the supranational jurisdictional control exereised by the Court of Justice. Some commentators go as far as to sustain that certain Court rulings may be qualified as a "pacific judicial revolution". The purpose of this essay is to demonstrate how the Court of Justice through a few landmark rulings has paved the way to exercise the jurisdictional control of the Community, conferring thereby effectiveness to the Community's legal framework and assuring the consolidation of such integration process. Moreover, some reflections are made as to whether this resolution of disputes system may fit into the Mercosur.
\end{abstract}

Unitermos: solução de disputas; União Européia; Tribunal de Justiça da União Européia; controle jurisdicional; Direito Comunitário; eficácia; doutrina do efeito direto; primazia do Direito Comunitário; instituição supranacional; soberania; delegação de competência; Mercosul; Protocolo de Olivos.

\section{Introdução.}

Dentre as inúmeras rupturas institucionais nas estruturas jurídicas do Estado, geradas pelo convencionalmente denominado fenômeno da globalização 
econômica, destaca-se, sem dúvida, como pondera José Eduardo Faria, o esvaziamento da soberania e da autonomia dos Estados nacionais.' Ao longo do tempo, uma nova concepção de soberania, embasada na crescente aceitação de uma ordem jurídica supranacional, foi-se sobrepondo ao conceito clássico-tradicional, que teve sua origem na necessidade de consolidação da territorialidade do Estado moderno.

Pode-se afirmar que essa nova concepção de soberania é um desdobramento contemporâneo da visão grociana que traz subjacente a idéia da interdependência e do funcionalismo, os quais limitam alcance dela por força da construtiva reciprocidade de interesses comuns. Esses interesses comuns, como lembra Celso Lafer, encontram seu exemplo mais desenvolvido e adiantado na União Européia, uma experiência sobretudo econômica de integração, caracterizada pela delegação de competências das soberanias a instituições supranacionais. ${ }^{2}$

Os Tratados que instituíram as Comunidades Européias permitiram a formação gradativa de uma nova ordem supranacional, na qual a aplicação de normas jurídicas passou sujeitar-se a um Tribunal de Justiça, com a primazia do Direito Comunitário sobre o Direito interno de cada Estado-Membro. Trata-se, pois, de um novo fenômeno das relações internacionais.

A afirmação de que a construção bem-sucedida do mercado comum e do processo de integração da União Européia (i.e., desse "novo fenômeno das relações internacionais") pode ser atribuída exclusivamente ao papel desempenhado pelo Tribunal de Justiça seria, para dizer o mínimo, pouco científica, além de estar impregnada do que Alain Goulene muito apropriadamente denominou de "positivismo esclerosado" 3 Claro está que qualquer análise a respeito não poderia prescindir de uma série de fatores politicos, culturais, históricos e econômicos que tiveram influência decisiva na conformação da Comunidade.

Contudo, a prática tem demonstrado que a evolução desse processo de integração deve-se, em larga medida, à existência do controle jurisdicional supranacional exercido pelo Tribunal de Justiça. Para alguns, inclusive, como Robert Lecourt, as decisões proferidas pelo Tribunal de Justiça podem sẹ qualificadas como uma verdadeira e "pacífica revolução judicial"4

O objetivo deste artigo é demonstrar como, por meio de algumas decisões históricas, o Tribunal de Justiça abriu caminho para exercer efetivamente o controle jurisdicional da Comunidade, conferindo eficácia a seu ordenamento jurídico e assegurando, conseqüentemente, a consolidação do processo de integração.

1. Cf. Josć Eduardo Faria, Direito e Globalização Econômica, Josć Eduardo Faria org., São Paulo, Malhciros Editores, 1996, Introduçào, p. II.

2. Ver Cclso Lafer, Desafios: élica e política, Sào Paulo, Siciliano, 1995, p. 233.

3. Cf. Alain Goulene, "Supranacionalidade da Justiça: cfetividade da integração cconômica regional c proteção dos dircitos subjetivos", in Contratos Internacionais e Direito Econômico no Mercosul, org. Paulo Borba Casclla et al., São Paulo, Ltr, 1996, p. 314.

4. Ver a respeito Robert Lecourt, L'Europe des Juges, Bruxclas, Bruylant, 1976. 


\section{Estrutura institucional da União Européia.}

O que distingue a União Européia ${ }^{5}$ da maioria das organizações internacionais é justamente a existência de um sofisticado conjunto de instituições que gozam de poderes autônomos e que lhe permitem implementar seus objetivos. Possuem essas instituições a tarefa de supervisionar o processo de integração econômica, gerando e assegurando a eficácia da legislação comunitária pertinente. A evolução da Comunidade tem visto muitas modificações formais e informais no papel e no relacionamento entre as instituições.

O Conselho é o órgão que representa os interesses individuais de cada Estado-Membro e tem a incumbência de definir as principais políticas da Comunidade. Sua composição varia conforme a natureza do assunto em discussão. Se se tratar de assuntos ligados à agricultura, por exemplo, os ministros da Agricultura dos EstadosMembros é que se reunirão para debatê-los; se se tratar de assuntos financeiros serão os Ministros dos Estados-Membros encarregados dessa Pasta a se encontrar. Se, por outro lado, a matéria em pauta estiver relacionada a assuntos de interesse geral da Comunidade, os ministros das Relações Exteriores comporão o Conselho. A presidência do Conselho é exercida rotativamente por seus integrantes, por períodos de seis meses.

A Comissão, ao contrário, é o órgão representativo dos interesses da Comunidade, administrando-a em seu dia-a-dia. A Comissão supervisiona a correta aplicação dos tratados e, se necessário, toma medidas contra os Estados-Membros que violam as normas comunitárias. É integrada por nacionais indicados pelos Governos dos Estados-Membros, os quais devem agir, no entanto, somente no interesse da Comunidade. A Comissão é dividida em Diretórios Gerais que desenvolvem e executam políticas nas diversas áreas de competência da Comunidade. O Diretório DG IV responde pela área de concorrência.

O Parlamento que, desde 1979, tem seus membros diretamente eleitos, é integrado por representantes agrupados conforme sua filiação a correntes políticas e não pelo critério da nacionalidade. Seus poderes sobre o Tratado da CEE foram severamente limitados. Possuia apenas alguns direitos de participação no processo legislativo e de supervisão das atividades da Comissão. Também exercia uma tênue influência informal sobre a Comissão e o Conselho. Esses fracos poderes do Parlamento que, afinal, é o único órgão comunitário eleito pelo povo, deixou a Comunidade sujeita a críticas por sua falta de democracia. Por essa razão, desde o Ato Único Europeu, ainda que de maneira cautelosa, seus poderes têm sido gradativamente aumentados. Com o Tratado da União Européia, foi, pela primeira vez, atribuído ao Parlamento o direito de veto sobre propostas legislativas em algumas áreas. A pressão para um aprimoramento radical da democracia no âmbito da Comunidade continua em alta na agenda institucional.

5. Adota-sc aqui a expressão "tratado", significando "Tratado da União Européia", com as altcraçõcs introduzidas pclo Tratado de Amsterdã de I" de maio de 1999. Em 1995, com a adesão da Áustria, Sućcia c Finlândia, a Comunidade passou a scr composta por quinze Estados-Mcmbros. 
O Tribunal de Contas é considerado o representante dos contribuintes e a "consciência financeira" da União Européia, na expressã̃o de Ari Beltran. É encarregado de comprovar, de forma independente, que as instituições investem os fundos comunitários seguindo as normas propostas e para os objetivos previstos. ${ }^{6} \mathrm{O}$ Coreper, o Conselho de Representantes Permanentes dos Estados-Membros ante as Comunidades Européias, é um órgão cada vez mais importante na atividade do Conselho, embora este tenha as faculdades da decisão. Outros órgãos quẹ também devem ser citados: o Comitê Econômico Social, o Comitê das Regiões, o Banco Europeu de Investimentos, o Banco Central Europeu, o Comitê Monetário e o Instituto Monetário Europeu. ${ }^{7}$

O Tribunal, braço judicial da Comunidade, é sua maior instituição. Localizado em Luxemburgo, é composto de juízes dos diferentes Estados-Membros. Obviamente, ao serem nomeados para o Tribunal, tornam-se juízes da Comunidade, "untainted by national bias", como dizem Wheatherill e Beaumont $t^{8}$. O Tribunal conta com a assistência dos chamados Advogados-Gerais, os quais apresentam pareceres sobre os casos antes de seu julgamento. Como se verá ao longo deste artigos, apesar de serem fundamentais para a avaliação dos casos pelo Tribunal, tais pareceres não têm caráter vinculante.

Pode-se afirmar que o aspecto mais importante da função do Tribunal é sua competência para decidir questões que lhe são formuladas pelos tribunais dos Estados-Membros, a título prejudicial, na forma prevista no art. 234 do Tratado que prescreve "verbis":

“Art. 234 O Tribunal de Justiça é competente para decidir, a título prejudicial:

a) Sobre a interpretação do presente Tratado.

b) Sobre a validade e a interpretação dos atos adotados pelas instituições da Comunidade e pelo $B C E$.

c) Sobre a interpretação dos estatutos dos organismos criados por ato do Conselho, desde que estes estatutos o prevejam.

Sempre que uma questão desta natureza seja suscitada perante qualquer órgão jurisdicional de um dos Estados-Membros, esse órgão pode, se considerar que uma decisão sobre essa questão é necessária ao julgamento da causa, pedir ao Tribunal de Justiça que sobre ela se pronuncie.

Sempre que uma questão desta natureza seja suscitada em processo

6. Cf. Ari Possidonio Beltran, Os Impactos da Integração Econômica no Direito do Trabalho: globalização e direitos sociais, São Paulo, LTr, 1998, p. 39.

7. Ibid, pp. 39-40.

8. Cf. Stephen Weatherill c Paul Bcaumont, EC Law: the essential guide to the legal workings of the European Community, Londres, Pcnguin Books, 1993, p. 30. 
pendente perante um órgão jurisdicional nacional cujas decisões não sejam suscetiveis de recurso judicial previsto no direito interno, esse órgão é obrigado a submeter a questão ao Tribunal de Justiça" 9

Em regra, nenhuma questão ou controvérsia surgida no âmbito da Comunidade entre nacionais ou empresas ou, ainda, entre particulares e autoridades nacionais dos Estados-Membros é trazida diretamente ao Tribunal, devendo ser antes apreciada pelos tribunais nacionais. Daí ser o art. 234 essencial para a preservação da natureza comunitária da legislação emanada do Tratado. Com efeito, o art. 234 assegura que, em quaisquer circunstâncias, referida legislação seja a mesma em todos os Estados-Membros.

Como assinalado por Neville, a aplicação uniforme do Direito Comunitário é a base do mercado comum. Se aplicado pelos tribunais nacionais, o Direito Comunitário "would be liable to fragment and become overlaid by the national legal systems. In the absence of a federal structure or of any Community appellate court, the preliminary ruling is the only means by which uniform application of Community law can be attained" 10

De fato, a função da questão prejudicial é mais bem explicada pela própria natureza "sui generis" do Direito Comunitário. O Direito Comunitário é, por sua natureza, um Direito interno comum dos Estados-Membros e não um Direito que regule as relações entre eles. Assim, na ausência de uma estrutura federativa, é natural que as políticas comunitárias sejam implementadas pelas autoridades dos Estados-Membros e o Direito Comunitário aplicado, com base nas interpretações do Tribunal, pelos tribunais nacionais. Assim, diz Neville, "it is to be expected that, in the normal way, Community Law is enforced through the national courts, which...have an exclusive jurisdiction to apply it in disputes between individuals, and between the individual and the authorities of the Member States" E, arremata: "conflicts of jurisdiction between a national court and the Court of Justice can therefore rarely arise, but the exact demarcation line may be a delicate one to draw"

Pela importância que o papel desempenhado pelo Tribunal, com lastro no art. 234 do Tratado, tem para o desenvolvimento deste estudo, vale a pena transcrever o seguinte trecho de autoria de Bingham, citado por Neville, que explica cristalinamente as razões pelas quais o Tribunal está mais bem aparelhado para decidir sobre as questões comunitárias:

Sitting as a judge in a national court, asked to decide questions of Community Law, I am very conscious of the advantages enjoyed by the Court of Justice. It has a panoramic view of the Community and its

9. Antigo artigo 177.

10. Ver Neville L. Brown, The Court of Justice of the European Communities, $3^{3} \mathrm{ed}$., Londres, Sweet \& Maxwell, 1989, pp. 174/175.

11. Ibid., pp. 178/179. 
institutions, a detailed knowledge of the treaties and of much subordinate legislation made under them, and an intimate familiarity with the functioning of the Community market which no national judge denied the collective experience of the Court of Justice could hope to achieve. Where questions of administrative intention and practice arise the Court of Justice can receive submissions from the Community institutions, as also where relations between the Community and non-member states are in issue. Where the interests of member states are affected they can intervene to make their views known... Where comparison falls to be made between Community texts and different languages, all texts being equally authentic, the multinational Court of Justice is equipped to carry out the task in a way which no national judge, whatever his linguistic skills, could rival. The interpretation of Community instruments involves very often not the process familiar to common lawyers of laboriously extracting the meaning from words used but the more creative process of supplying flesh to a spare and loosety constructed skeleton. The choice between alternative submissions may turn not on purely legal considerations, but on a broader view of what the orderly development of the Community requires. These are matters which the Court of Justice is very much better placed to assess and determine than a national court" 12

Claro está, pois, que, se aos Estados-Membros fosse confiada a tarefa de interpretar o Direito Comunitário, haveria, sem nenhum exagero, tantos ordenamentos jurídicos comunitários quantos fossem os ordenamentos jurídicos nacionais de cada um dos Estados-Membros.

Em 1989, por força das determinações do Ato Único Europeu, foi criado o Tribunal de Primeira Instância para, em um certo sentido, aliviar a carga de trabalho do Tribunal. Tem sua competência estabelecida e limitada pelo art. 225 do Tratado, não podendo julgar ações propostas pelos Estados-Membros ou pelas instituições da Comunidade. Tampouco tem competência para conhecer das questões prejudiciais submetidas nos termos do art. $234 .^{13}$

\section{Ibid. , pp. 175/176.}

13. Estabclccem os parágrafos primciro c scgundo do art. 225 do Tratado: "I. É associada ao Tribunal da Justiça uma jurisdição encarregada de conhecer en primeira instância, sem prejuizo de recurso para o Tribunal de Justiça limitado às questões de dircito e nas condiçōes estabelecidas pelo respectivo Estatuto. de certas categorias de açöes determinadas nas condições definidas no n. 2. O Tribunal de Primeira Instância não tem competência para conhecer das questôes prejudiciais submetidas nos termos do art. 234. 2. A pedido do Tribunal de Justiça e após consulta do Parlamento Europen e da Comissão, o Conselho, deliberando por unanimidade, determina as categorias de ações a que se refere o n. I e a composição do Tribunal de Primeira Instância e adota as necesssárias adaptações e disposições complementares ao Estatuto do Tribunal de Justiça. Salvo decisão em contrário do Conselho, são aplicáveis ao Tribunal de Primeira Instância as disposiçōes do presente Tratado relativas ao Tribunal de Justiça, e nomeadamente as disposições do Protocolo relativo ao Estatuto do Tribunal de Justiça" 


\section{A legislação comunitária.}

O Direito primário da Comunidade ${ }^{14}$ é formado por seus tratados constitutivos. O Direito Comunitário derivado tem sua fonte formal nos atos unilaterais das instituições da Comunidade.

Nos termos do art. 249 do Tratado, para o desempenho de suas funções, o Parlamento, em conjunto com o Conselho, o Conselho e a Comissão "adotam regulamentos e diretivas, tomam decisões e formulam recomendações e pareceres" $\mathrm{O}$ regulamento tem caráter geral, sendo obrigatório em todos os seus elementos e diretamente aplicável em todos os Estados-Membros. Já a diretiva vincula o EstadoMembro destinatário quanto ao resultado a alcançar, deixando, no entanto, às instâncias nacionais a competência quanto à forma e aos meios ou, como explica Maristela Basso, permite "aos Estados-Membros escolherem a sua forma de aplicação"'s . A decisão é obrigatória em todos os seus elementos para os destinatários que designar. ${ }^{16}$ Por fim, as recomendações e os pareceres não são vinculantes.

Como observa Guido Fernando Soares, inexiste no Tratado qualquer definição enumerativa dos assuntos que deverão ser legislados sob a forma de regulamentos, diretivas, decisões, recomendações ou pareceres. Na verdade, diz ele, "a denominação do ato tem implicações nos seus efeitos em relação aos EstadosPartes e em relação ao cumprimento dos objetivos da Comunidade Européia". Assim, o regulamento cumpre a função de realizar o Direito Uniforme, "pedra angular da integração regional" A diretiva desempenha a tarefa de aproximạr e harmonizar as disposições legislativas, regulamentares e administrativas dos Estados-Membros, "constituindo um instrumento plástico de uniformização parcial e possivel, uma vez que aos poderes legiferantes domésticos são deixadas as atribuições das grandes linhas gerais da política legislativa comunitária" A decisão, prossegue o autor, constitui "um poderoso instrumento de influir, no sentido de reformar, as decisões isoladas dos Estados ou de pessoas fisicas ou juridicas sob a jurisdição dos mesmos". Por fim, as recomendações e pareceres "previnem qualquer feitura de atos (administrativos,

14. Sempre lembrando que cstamos nos referindo às três Comunidades, cmbora haja pequenas diferenças formais cntre alguns desses scus atos unilatcrais, cuja análise refoge aos objetivos deste cstudo. Ver a respeito Celso D. de Albuquerque Mello, Dircito Internacional da Integração, Rio de Janciro, Renovar, 1996, pp. 139 a 178.

15. Cf. Maristcla Basso, "Livre circulação de mercadorias e a proteção ambiental no Mercosul", in Mercosul: seus efeitos juridicos, econômicos e politicos nos Estados-Membros, org. Maristela Basso, Porto Alcgrc, Livraria do Advogado, 1995, p. 198.

16. Como sublinhado por Casclla, "a aplicabilidade direta de Decisão, dirigida a um Estado-Membro, normalmente é recusada: e os particulares, normalmente, não podem fazer valer direitos ou obrigaçòes, com base em Decisão" Contudo, prosseguc o autor, "pode também ocorrer a aplicabilidade direta da Decisão, produzindo efeito juridico imediato na ordem interna dos Estados-Membros...sobretudo em dois exemplos..., com interesse todo especial, en matéria de direito da concorrência...". Referc-sc cle aos arts. 85 c 86 (atuais $81 \mathrm{c} 82$ ) do Tratado. Cf. Paulo Borba Casclla, Comunidade Européia.., op.cit., pp. $138 / 139$. 
legislativos por parte dos Estados ou suas autoridades ou jurídicos de direito privado, leia-se "contratos") que possam contrariar as normas comunitárias" 17

Vale aduzir, por fim, que o Tribunal tem competência para examinar a legalidade dos regulamentos, diretivas e decisões. De acordo com o art. 230 do Tratado, "o Tribunal é competente para conhecer dos recursos com fundamento em incompetência, violação de formalidades essenciais, violação do presente Tratado ou de qualquer norma juridica relativa à sua aplicação, ou em desvio de poder, interpostos por um Estado-Membro, pelo Conselho ou pela Comissão". Da mesma forma, qualquer "pessoa singular ou coletiva pode interpor, nas mesmas condições, recurso das decisões de que seja destinatária e das decisões que, embora tomadas sob a forma de regulamento ou de decisão dirigida a outra pessoa, lhe digam direta e individualmente respeito".

4. O Tribunal e a eficácia do processo de integração.

Conforme já ponderado anteriormente, a afirmação de que a construção de bom êxito do mercado comum e do processo de integração da Comunidade pode ser atribuída exclusivamente ao papel desempenhado pelo Tribunal seria, para dizer o mínimo, pouco científica, além de estar impregnada de um "positivismo esclerosado". Nos limites traçados para este estudo, porém, cabe apenas demonstrar a importância que o Tribunal teve e tem tido na formação desse processo de integração europeu.

Para poder desenvolver o mercado comum, tiveram os Estados-Membros de definir o contorno institucional da Comunidade, isto é, optar entre uma concepção diplomática e federalista. Em decorrência da opção feita pelo federalismo, estão os Estados-Membros submetidos em comum às regras de Direito Comunitário, o qual também pode ser qualificado como um sistema jurídico de caráter supranacional. Participam, assim, os Estados-Membros da elaboração das regras comunitárias, cuja aplicação, como se verá mais adiante, se torna efetiva dentro dos Estados, aos Estados e pelos Estados. E a efetividade do direito é, como enfatiza Golene, "condicionada à existência de tribunal, ou, pelo menos, à existência de terceiro, árbitro independente e capaz de ditar o direito e a sanção de sua aplicação" 18

Nesse diapasão, salienta Hartley que: "The supranational element in the Community constitution would be ineffective without a Court. The most important functions of the Court of Justice of the European Communities- to give it full official name-are to ensure that the law is enforced, irrespective of political considerations (specially against Member States); to act as referee between the Member States and

17. Cf. Guido Soares, "Mercosul - Órgãos Législadores e Administrativos" (cstudo cncaminhado cm maio de 1993, ao Governador André Franco Montoro, Presidente do Instituto Latino Amcricano de São Paulo, ILAM, sob o contrato com o PNUD). Ver também do autor "A Atividade Normativa do Mercosul, nos Dois Primeiros Anos de Vigência do Tratado de Assunção: um Balanço Positivo?", in Boletim de Integração Latino-Americana, nº12 -MRE/SGIE/NAT, pp. 11/12.

18. Ibid., p. 313. 
the ommunity as well as between the Community institutions inter se; and to protect the rigths of the individual from infringement by the Brussels bureaucracies. Those functions are specially important in view of the fact that the democratic element is still weak in the Community". 19

A condição para eficácia do projeto de integração europeu se realiza, assim, pelas amplas competências outorgadas ao Tribunal. Um Tribunal supranacional é, como diz Goulene, "uma condição para a existência do jurídico que conduz, por sua vez, a uma efetividade do direito comunitário" 20 O Tratado da União Européia, vale lembrar, não trouxe muitas inovações do ponto de vista institucional, tendo procurado, apenas, conciliar a natureza federativa da Comunidade com a eficácia supranacional do Tribunal. Veio, na verdade, fortalecer a natureza federativa da Comunidade, na medida em que outorgou poderes ao Tribunal para aplicar sanções pecuniárias.

Saliente-se, também, que outros órgãos comunitários, como a Comissão, igualmente têm contribuído para a eficácia da ordem jurídica supranacional. Com efeito, a credibilidade da Comissão deve-se à sua imparcialidade. Os Estados-Membros dispõem-se a aceitar seu papel porque acreditam que ela esteja acima de rivalidades - nacionais. A grande fraqueza da Comissão, porém, é que lhe falta base política. Não se encontra em condições de apelar à opinião pública contra atitudes dos Governos dos Estados-Membros como poderia fazê-lo se seus membros fossem indicados, por exemplo, pelo Parlamento.

Seja como for, ainda que outros órgãos, como a Comissão, participem ativamente do aperfeiçoạmento do processo de integração, é forçoso reconhecer que o trabalho do Tribunal tem sido dos mais cruciais, sobretudo após ter consagrado a primazia do Direito Comunitário sobre o Direito Interno, fato que, indiscutivelmente, abriu caminho para a consolidação definitiva do processo de integração.

5. O Tribunal e a "constitucionalização" da estrutura jurídica comunitária.

5.1. A doutrina do efeito direto.

Como se sabe, o Tratado foi concebido de maneira a conter termos e princípios gerais, sobretudo nas áreas relativas a políticas sociais, econômicas e monetárias internas. Sua vagueza e suas ambigüidades foram intencionais ou, dito de outra forma, constituíram o resultado inevitável de uma "fórmula compromisso", que deixou para um Tribunal imparcial a tarefa de desenvolver a Comunidade "in the light of experience", como afirma Gordon Slynn. ${ }^{21}$ Nessa conformidade, a partir de 1963, o

19. Ver Hartley, TC, The Foundations of European Community Law, $2^{4}$ cd., Oxford, Clarcndon Press, 1988, p.49.

20. Cf. Goulenc, "Supranacionalidadc...", op.cit., p. 323.

21. Ver Gordon Slynn, "The Court of Justice of the European Communities", [1984] 33 ICLQ, p. 409. 
Tribunal, em uma série de julgados, acabou por estabelecer doutrinas fundamentais que fixaram o relacionamento entre a Comunidade e os Estados-Membros.

A primeira dèlas consubstancia-se no entendimento pelo Tribunal, manifestado no caso Van Gend en Loos, ${ }^{22}$ de que a Comunidade constitui uma "nova ordem jurídica" que confere direitos a seus indivíduos. Alguns dispositivos do Direito Comunitário são diretamente aplicáveis nos Estados-Membros na medida em que criam "individual rights which national courts must protect without any need for implementing legislation in that member state" ${ }^{23}$ Trata-se do efeito direto das diretivas e decisões dirigidas aos Estados-Membros. ${ }^{24}$

A doutrina do efeito direto parte da seguinte premissa: normas comunitárias que forem claras, precisas e, em um certo sentido, "auto-suficientes" (ou seja, que não demandarem medidas legislativas adicionais pelas autoridades da Comunidade ou dos Estados-Membros) têm de ser consideradas como se fossem normas internas do Estado-Membro no campo de aplicação do Direito Comunitário. O efeito direto aplica-se a todas as ações que produzem efeitos legais na Comunidade, isto é o Tratado e a legislação secundária. Ademais, opera não-somente no sentido de criar obrigações jurídicas entre particulares e Estados-Membros, mas também entre os próprios particulares. Como parte da lei interna do Estado-Membro, as normas comunitárias podem ser invocadas perante o judiciário de cada um dos Estados-Membros, o qual deve estar suficientemente aparelhado para dar-lhes a necessária eficácia.

As implicações dessa doutrina foram e continuam sendo extremamente abrangentes. Com efeito, o Tribunal "reversed the normal presumption of public international law whereby international legal obligations are result-oriented and addressed to states". ${ }^{25}$ Nos moldes do Direito Internacional Público clássíco, é permitido à ordem constitucional interna do Estado-Membro determinar o método pelo qual as obrigações internacionais irão produzir efeitos dentro de seu ordenamento jurídico e a extensão das mesmas. Mesmo quando uma obrigação internacional, tal como um acordo de comércio ou uma convenção de direitos humanos, prevê a outorga de direitos (ou obrigações) para indivíduos dentro do Estado, se tal Estado deixar de outorgar tais direitos, não podem tais indivíduos invocar o cumprimento de uma obrigação internacional perante seus tribunais, a menos que a Constituição interna, que, geralmente, é indiferente ao Direito Internacional Público, prescreva tal remédio legal.

22. Caso Van Gend en Loos v Nederlandse Administratie der Belastingen, [1963] ECR I.

23. ibid., p.13.

24. Como discutido precedentementc, as dirctivas c as decisões dirigidas aos Estados-Mcmbros, à diferença do regulamento, nào gozam de aplicabilidade dircta. $\mathrm{O}$ cfeito dircto, criação jurisprudencial, consistc exatamente na possibilidade de os particulares invocarem $\mathrm{cm}$ tribunais nacionais, se a natureza $\mathrm{c}$ os termos da norma ou do ato assim o permitirem, uma disposição dos tratados comunitários ou um ato de dircito derivado para afastar a aplicaçào de uma norma do Estado-Mcmbro.

25. Cf. J.H.H. Weiler, "The Transformation of Europe", [1991] The Yalc Law Journal, v. 100, n. 8, p. 2.413 . 
Na prática, portanto, depois de Van Gend en Loos, os Estados-Membros que violassem suas obrigações comunitárias não mais poderiam deslocar a disputa para o plano do contencioso entre Estados. Eles passaram a estar sujeitos ao ajuizamento de ações, visando ao cumprimento das normas comunitárias perante seus próprios tribunais. A respeito, Weiler arremata:

\begin{abstract}
"Effectively, individuals in real cases and controversies (usually against state public authorities) became the principal "guardians" of the legal integrity of Community Law within Europe similar to the way that individuals in the United States have been the principal actors in ensuring the vindication of the Bill of Rights and other federal law"26
\end{abstract}

O pleno impacto do conceito do efeito direto da norma comunitária só foi possível com o desenvolvimento da segunda doutrina de "constitucionalização" do Direito Comunitário, que é a supremacia deste último sobre o Direito Interno dos Estados-Membros. A combinação dessas duas doutrinas, como se verá na seqüiência, significa que as normas comunitárias que produzem efeitos diretos não constituem meramente "Leis de Direito Interno" mas, sim, as "Leis Máximas" do Estado-Membro. Paralelismos com essa arquitetura constitucional, com poucas exceções, são encontráveis na ordem constitucional interna de Estados Federais.

\title{
5.2. A primazia do Direito Comunitário.
}

A exemplo do efeito direto, é preciso notar que a primazia do Direito Comunitário sobre o Direito Interno dos Estados-Membros, pedra fundamental da ordem jurídica comunitária e conseqüência imediata da delegação de poderes soberanos pelos Estados-Membros à Comunidade, não foi estabelecida explicitamente pelo Tratado, nem por quaisquer de suas modificações subseqüentes. Na verdade, foi o Tribunal, em decisão proferida no Caso Costa v ENEL, ${ }^{27}$ que firmou jurisprudência a respeito.

Com efeito, o Tribunal, ao se utilizar de uma interpretação contextual do Tratado, chegou à conclusão de que o Direito Comunitário tinha precedência sobre o Direito Interno. A ênfase conferida aos princípios gerais do Tratado pode ser vista no seguinte parágrafo em que o Tribunal faz referência ao fato de os Estados-Membros terem limitado seus direitos de soberania ao criarem a Comunidade e outorgarem poder legiferante às suas instituições: "By creating a Community of unlimited duration, having its own institutions, its own personality, its own legal capacity and capacity of representation on the international plane and, more particularly, real powers stemming from a limitation of sovereignty or a transfer of power from the States to the Community, the Member States have limited their sovereign rights, albeit within limited fields, and have thus created a body of law which binds both their nationals and themselves. The

26. ibid., p. 2.414 .

27. Caso 6/64, Costa v ENEL, [1964] ECR 585. 
integration into the laws of each Member State of provisions which derive from the Community, and more generally, the terms and the spirit of the Treaty, make it impossible for the States, as a corollary, to accord precedence to a unilateral and subsequent measures of a legal system accepted by them on a basis of reciprocity". ${ }^{28}$

Do argumento da transferência de soberania, o Tribunal extraiu a conclusão de que o Direito Comunitário configurava algo de especial ("la spécificité du droit communautaire"). A partir de tal especificidade, deduziu a supremacia do Direito Comunitário.

O Tribunal também levou na devida conta algumas das possíveis consequiências para diversos dispositivos do Tratado, caso o Direito Comunitário não viesse a prevalecer sobre o Direito Interno de cada um dos Estados-Membros. Em especial, o Tribunal referiu-se aos art. $5^{\circ}$ (atual art. 10), que prescreve a obrigação de os Estados-Membros se absterem de tomar quaisquer medidas suscetíveis de pôr em perigo a consecução dos objetivos do Tratado, e $189^{29}$ (atual 249), que dispõe sobre os regulamentos, diretivas, decisões e recomendações, concluindo que tais dispositivos "would lose their purpose if Member States could renounce their obligations by means of an ordinary law" 30

Por outras palavras, se "as normas comunitárias pudessem ser anuladas por uma qualquer lei nacional, estaria igualmente excluida a aplicação uniforme do Direito Comunitário. Dessa maneira, o funcionamento da Comunidade seria posto em causa e a construção de uma Europa unida estaria definitivamente comprometida" 31

Trata-se, pois, de exemplo em que o Tratado é silente acerca do assunto específico, mas dá claras indicações em seu texto quanto à sua melhor interpretação. Rasmussen, no entanto, discorda dessa afirmação, ao declarar que o Tribunal, nesse caso "pushed its gap-filling activities beyond the proper scope of judicial involvement in society's law and policy making [in] the judgments stating that...Community law must be considered the supreme law of the land" 32

De qualquer forma, no entendimento do Tribunal, a Comunidade vai muito além dos tratados internacionais tradicionais que apenas estabelecem relações entre os Estados-Partes contratantes, na medida em que cria instituições com poderes legiferantes, os quais, por sua vez, geram direitos e obrigações para pessoas fisicas e jurídicas dos Estados-Membros.

28. Ibid., pp. 593-4.

29. Este artigo já havia sido modificado anteriormente no sentido de atribuir competência ao Parlamento Europeu para, juntamente com o Consclho $\mathrm{c}$ a Comissão, claborar regulamentos $\mathrm{c}$ emitir dirctivas, tomar decisões $\mathrm{c}$ fazer recomendações.

30. Caso 6/64, Costa v. ENEL, [1964] ECR 585, p.594.

31. Cf. Elizabcth Accioly, in Mercosul \& União Europeia: estrutura juridico-institucional, Curitiba, Juruá Editora, 1996, p. 96.

32. Ver Hjaltc Rasmussen, On Law and Policy in the European Court of Justice, Dordrecht, Boston c Lancastcr, Martinus Nijhoff Publishers, 1986, p. 28. 
Mais tarde, em 1991, o Tribunal referiu-se ao Tratado como "a carta constitucional de uma Comunidade baseada no Estado de Direito ("constitutional charter of a Community based on the rule of law"). O Tribunal, como bem lembram Weatherill e Beaumont, modificou inclusive sua afirmação no Caso Costa v. ENEL relativamente às "áreas restritas" em que os Estados-Membros limitam sua soberania, para declarar que tais direitos de soberania são limitados em "ever wider fields". Nesse ponto, prosseguem os autores, o Tribunal revelou estar consciente da extensão da competência da Comunidade acordada no Ato Único Europeu, e em Maastricht, nos dias 9 e 10 de dezembro de 1991. Naquele estágio da evolução da Comunidade, arrematam, "the Court maintained that the two of the essential provisions of the Community constitution that had been firmly established were the primacy of Community law over the law of the member states and the direct effect of a whole series of Community law provisions". ${ }^{33}$

\section{O primado constitucional do Direito Comunitário.}

Como visto, a ordem jurídica comunitária só sobrevive na medida em que o seu respeito e a sua proteção sejam garantidos. Garantias essas constituidas pelo efeito direto e pelo primado do Direito Comunitário sobre o direito nacional. Esses princípios, para cuja existência o Tribunal contribuiu de forma decisiva, "garantem a aplicação uniforme e prioritária do direito comunitário em todos os EstadosMembros" 34

O Direito Comunitário, portanto, porque dá corpo à concepção comunitária, que, como diz Fausto Quadros, "exprime a superioridade da agregação sobre a desagregação" ${ }^{35}$ tem como característica intrínseca a uniformidade da sua interpretação e da sua aplicação na ordem interna dos Estados-Membros. Para tanto, é preciso que seu primado seja absoluto e incondicional sobre todo o Direito nacional, aí incluidas as respectivas Constituições.

É por isso que Pierre Pescatore salienta que o primado constitucional é uma "exigência existencial do direito comunitário. Sem primado sobre a Constituição não há direito comunitário e não há Comunidade" 36

Assim é que, após estabelecer, no Caso Costa v. ENEL, o princípio da primazia do Direito Comunitário sobre o Direito Interno comum ou legislação infraconstitucional, deparou o Tribunal, no Caso Internationale Handelsgesellschaft, ${ }^{37} \mathrm{com}$

33. Ver Stephen Weatherill c Paul Bcaumont, in EC LAW: the essential guide..., op.cit., pp. $315 / 316$. Os autores basciam-sc cm parecer accrca do projeto do Tratado da Árca Econômica Européia, publicado $\mathrm{cm}$ [1992] I CMLR 245.

34. Cf. Elizabcth Accioly, Mercosul..., op.cit., p. 98.

35. Cf. Fausto Quadros, Apud Elizabeth Accioly, Mercosul \& União Européia..., op. cit., p. 97.

36. Cf. Picrre Pescatorc, citado por Fausto Quadros $\mathrm{cm}$ texto reproduzido por Elizabcth Accioly, Mercosul..., op.cit., p.98. 
a questão da supremacia do Direito Comunitário sobre as Constituições dos EstadosMembros e, em particular, sobre as disposições referentes a direitos fundamentais contidos em tais Constituições. O Tribunal enfatizou a necessidade de se preservar a uniformidade e eficácia do Direito Comunitário em todos os Estados-Membros, as quais seriam prejudicadas se os Estados-Membros pudessem se valer de suas Constituições para anular as obrigações comunitárias. O Tribunal concluiu que "the validity of a Community measure or its effect within a Member State cannot be affected by allegations that it runs counter to either fundamental rights as formulated by the constitution of that State or the principles of a national constitutional structure" 38

Dessa forma, consolidou-se o entendimento de que a legislação comunitária também tem primazia sobre a Constituição dos Estados-Membros. Pouco tempo mais tarde, no Caso Itália v Comissão, ${ }^{39}$ o Tribunal simplesmente declarou que nenhum dispositivo de lei interna poderá ser invocado para revogar a lei comunitária. Restava ainda esclarecer se os Estados-Membros deveriam reservar a um tribunal em particular, como, por exemplo, um tribunal constitucional, algo equivalente ao Supremo Tribunal Federal no Brasil, a competência de aplicar a lei comunitária em detrimento da lei nacional ou interna.

No Caso Simmenthal, ${ }^{40}$ o Tribunal teve a oportunidade de apreciar essa questão. Declarou que mesmo um juiz “ $a$ quo" é obrigado a aplicar a lei comunitária ainda que, para tanto, tenha de desconsiderar as disposições internas sobre conflitos de leis. Como explicam Weatherill e Beaumont, o tribunal ou o juiz de primeira instância, conforme o caso, "must not wait for such provisions of national law to be set aside by legislation or by a constitutional court. Here the European Court is not requiring the national court to annul the provisions of national law that conflict with Community law but simply stating that it must not apply them" 41

Nos Estados-Membros, com exceção do Reino Unido que não possui Constituição escrita, todas as Constituições, mormente após as revisões constitucionais realizadas em decorrência do Tratado da União Européia, contêm dispositivos que aceitam a delegação do exercício de certas competências para um poder supranacional, "donde se conclui que os Estados-Membros devem ter mecanismos para recepcionar e acatar as leis comunitárias, que atuam nos limites por eles delegados" "42 Vejam-se alguns exemplos.

$\mathrm{Na}$ Grã-Bretanha que, como mencionado acima, não possui Constituição escrita, o "European Communities Act" de 1972, que dispõe sobre a adesão daquela à

37. Caso 11/70, Internationale Handelsgesellschaft v Einfuhr-und Vorratsstelle fïr Getreide und Futtemittel, [1970] ECR 1125.

38. ibid, p. 1.134.

39. Caso 48/7l, ltália v Comissão [1972] ECR 527, 532.

40. Caso 106/77, Amministrazione delle Finanze dello Stato v Simmenthal, [1978] ECR 629.

41. Cf. Weatherill c Bcaumont, EC LAW..., op. cit., p.317.

42. Ver Elizabeth Accioly, Mercosul \& União Européia, op. cit., p.118. 
Comunidade estabelece, em seu art. 2 (I), que: "All such rights, powers, liabilities, obligations and restrictions from time to time created or arising by or under the [Community] Treaties, and all such remedies and procedures from time to time provided for by or under the Treaties, as in accordance with the Treaties are without further enactment to be given legal effect or used in the United Kingdom shall be recognized and available in law, and be enforced, allowed and followed accordingly"

Na Alemanha, antes da revisão constitucional de 1992, a Constituição, em seu art. 24, já autorizava a transferência de poderes soberanos a instituições intergovernamentais. Nessa conformidade, de um modo geral, os tribunais daquele país não tiveram tantas dificuldades em aceitar a supremacia do Direito Comunitário. Como lembra Albuquerque Mello, já "houve quem afirmasse que na Alemanha a questão em análise não provocou tantos debates em virtude de uma "longa familiaridade dos juristas com o sistema federal" 43

É bem verdade, porém, que a questão envolvendo a supremacia do Direito Comunitário sobre os direitos fundamentais inalienáveis contidos na Constituição suscitou certa polêmica. No Caso Internationale Handelgesellschaft ${ }^{44}$ o "Bundesverfassungsgericht" (a Suprema Corte Alemã) posicionou-se no sentido de não renunciar a seu direito de aplicar os direitos fundamentais na Alemanha em face de um conflito com uma lei comunitária. A Suprema Corte Alemã, assim, acabou por não aceitar determinação do Tribunal no sentido de que o Direito Comunitário deveria prevalecer mesmo sobre os direitos fundamentais vigentes na Alemanha, ainda que reconhecesse que, naquele caso em particular, a lei comunitária não infringia tais direitos. O argumento utilizado pela Suprema Corte Alemã foi o de que o Parlamento não era eleito diretamente (isso em 1974) e que o Direito Comunitário não continha normas claras e precisas sobre direitos humanos fundamentais.

Mais tarde, em 1987, é que a Suprema Corte Alemã decidiu não mais examinar a compatibilidade da legislação comunitária com os direitos fundamentais vigentes na Alemanha, desde que o Tribunal continuasse a proteger adequadamente aqueles direitos.

Em 1992, foi feita uma revisão constitucional para adaptar não-somente a República Federal da Alemanha (pós-unificação), mas também seu federalismo ao novo contexto do Tratado da União Européia. Assim, o art. 23 foi redigido da seguinte forma: “A União Européia. 1. Para a edificação de uma Europa unida, a República Federal da Alemanha contribui para o desenvolvimento da União Européia que deverá respeitar os principios da democracia, do Estado de direito, do Estado social federativo

43. Ver Cclso D. de Albuquerque Mello, Direito Internacional da Integração, Rio de Janciro, Rcnovar, 1996, p. 210 , cmbasado $\mathrm{cm}$ reflexões de G. Sperdutti feitas no texto "Le principe de souveraineté et le problème des rapports entre le droit international et le droit inlerne", in Recueil des Cours de l'Academie de Droit International de la Haye, 1976, vol. v, t. 153, pp. 319 c ss, Martinus Nijhoff Publishers, The Haguc.

44. Caso II/70 Internationale Handelsgesellschaft v Einfihr- und Vorratsstelle fiu Getreide und Futtemittel, [1972] CMLR, 255. 
com o principio da subsidiariedade e que garante uma proteção dos direitos fundamentais substancialmente comparável à lei fundamental. Para este efeito, a Federação pode transferir direitos de soberania por uma lei aprovada pelo 'Bundesrat'...". ${ }^{45}$

Em outubro de 1993, o Tribunal Federal Constitucional alemão proferiu a denominada decisão de "Maastricht" a qual corroborou a constitucionalidade do Tratado da União Européia e abriu caminho para a participação da Alemanha no futuro do processo de integração. Algumas afirmações feitas por referido Tribunal alemão, porém, provocaram intensa preocupação no âmbito da Comunidade. Dentre elas, destaca-se a de que o Tribunal Federal Constitucional irá examinar se os atos legislativos emanados dos órgãos e instituições da Comunidade estão em conformidade ou extrapolam os poderes soberanos a ela transferidos.

Por outras palavras, como explica Steve J. Boom, "the Federal Constitutional Court, not the European Court of Justice (ECJ), will decide where the limits to European power lie, at least with respect to Germany" ${ }^{46}$

Ademais, declarou o referido Tribunal alemão que os atos legislativos da Comunidade que, em seu entendimento, excederem as competências delineadas no Tratado da União Européia, não terão efeito vinculante na Alemanha.

As implicações dessas declarações, como bem assinala o autor, são profundas. Podem colocar em risco a uniformidade do Direito Comunitário e o próprio futuro da integração. Afinal, o "danger to the central authority is not merely the occasional dramatic conflict over the legitimacy of one or another of its enactments, but the corrosive effect of continual challenges to its authority that cannot be resolved authoritatively" 47

$\mathrm{Na}$ França, o que se notou foi uma clara divisão entre as posições adotadas pelo "Conseil d'État" e a "Cour de Cassation". A "Cour de Cassation" várias vezes sustentou, de maneira consistente, a supremacia da lei comunitária sobre a francesa. $\mathrm{O}$ mesmo já não pode ser dito sobre o "Conseil d' État"

No passado, o "Conseil d'État" recusava-se a questionar a validade da lei francesa em face de um conflito com a lei comunitária. Tampouco aceitava a doutrina do efeito direto das diretivas, desconsiderando, conseqüentemente, suas obrigações previstas no art. 177 (3) (atual 234 (3)) do Tratado. ${ }^{48}$ Negava-se, ademais, a cumprir decisões do Tribunal nos casos que the eram submetidos.

45. Apud Elizabcth Accioly, Mercosul..., op. cit., pp. $118 / 119$.

46. Ver Steve J. Boom, "The European Union after the Maastricht decision: is Germany the 'Virginia of Europe? '", Harvard Law School, 1995, p. 2.

47. Ibid., Steve Boom, aqui, transcreve texto de Terrance Sandalow, "The Expansion of Federal Legislative Authority", in Courts and Free Markets 49, 51 (Terrace Sandalow c Eric Stcin, org.), 1982.

48. O art. 234 (3) cstabclecc: "Sempre que uma questào desta natureza seja suscitada em processo pendente perante um órgão jurisdicional nacional cujas decisòes näo sejam suscéptiveis de recurso judicial previsto no direito interno, esse órgão é obrigalo a submeter a questão ao Tribunal" 
Apenas mais recentemente, o "Conseil d'État" passou a dar sinais da sua disposição em aceitar a primazia do Direito Comunitário sobre o Direito Interno. Em 1990, incorporou o Direito Comunitário ao Direito francês e afirmou a submissão das leis francesas aos regulamentos comunitários. No Caso Boisdet, o "Conseil d" État", ao afirmar que uma lei nacional não pode servir de obstáculo à aplicação de um regulamento comunitário, acabou por anular uma decisão ministerial. ${ }^{40}$ Em 1992, nos Casos Rothmans e Philips, anulou decreto que conferia ao ministro do Orçamento o direito de fixar o preço do tabaco, afastando, assim, a incidência de lei de 1976 que infringia uma diretiva da Comunidade ${ }^{50}$

A exemplo da Alemanha, também a França adaptou sua Constituição à União Européia, uma vez que o Tratado da União Européia estabelece, "inter alia", uma união monetária, participação de estrangeiros em eleições municipais e a criação de uma cidadania européia que se sobrepõe à do Estado. Com efeito, prescreve o art. 88:

"Art. 88-1:

A República participa das Comunidades Européias e da União Européia, constituidas de Estados que escolheram livremente, em virtude dos tratados que as instituiram, de exercer em comum algumas de suas competências. $^{5 l}$

Art. 88-2:

Sob reserva de reciprocidade e conforme as modalidades previstas pelo tratado sobre a União Européia assinado em 7 de fevereiro de 1992, a França consente às transferências de competências necessárias ao estabelecimento da união econômica e monetária européia bem como a estipulação de regras relativas a travessia das fronteiras exteriores dos Estados-Membros da Comunidade Européia" \$2

Há, ainda, segundo lembra Albuquerque Mello, uma grande discussão na França acerca do alcance desse dispositivo constitucional. Alguns autores procuram distinguir as palavras "limitação" de "transferência" de soberania. Outros ponderam que se trata de uma questão tão sutil que resiste a qualquer análise. Para outros, toda limitação é uma transferência. ${ }^{53}$

49. Ver [1991] I CMLR 3, também comentado pela Comissão cm scu Oitavo Relatório Anual, Com (91) 321 , partc final.

50. Casos SA Rothmans International France e SA Philip Morris France: Société Arizona Tobacco Products e SA Philip Morris France mencionados cm Weathcrill c Bcaumont, EC Law.., op.cit, p.325.

51. Art. 88 da Constituição da República Francesa, com a redação dada pela revisão de 1992, conformc transcrição de Elizabcth Accioly, Mercosul..., op. cit., p. 119.

52. Apud Celso D. de Albuquerque Mello, Direito Internacional..., op. cit., p.214.

53. ibid., p. 215 . 
Na Itália, a Corte Constitucional refutou inicialmente a supremacia do Direito Comunitário sobre o Direito interno. Mais tarde, passou a aceitá-la sempre condicionado a que o Tribunal funcione como um instrumento efetivamente adequado de proteção aos direitos fundamentais no âmbito da Comunidade. Caso contrário, a Corte italiana reserva-se a possibilidade de interferir no sentido de fazer prevalecer os direitos fundamentais vigentes naquele Estado-Membro.

Como já referido anteriormente, foi no Caso Simmenthal ${ }^{54}$, que a Corte italiana acatou a orientação do Tribunal de que não era necessário aos juízes de primeira instância submeter à apreciação da Corte Constitucional conflitos entre a lei comunitária e a lei interna. Todos os órgãos jurisdicionais italianos ficavam, assim, obrigados a não aplicar medidas internas que fossem incompatíveis com o Direito Comunitário. De uma forma muito similar à do "Conseil d'État" francês, o "Consiglio di Stato" italiano, porém, tem manifestado ao longo do tempo certa relutância em aceitar a aplicabilidade direta da lei comunitária.

De qualquer forma, o art. 11 da Constituição italiana prescreve: " $A$ Itália...consente, em condições de paridade com os outros Estados, nas limitações de soberanias a uma ordem que assegure a paz e a justiça entre as nações; ajuda e favorece as organizações internacionais que tenham este objetivo" 5.

Em outros Estados-Membros, também houve, em maior ou menor intensidade, é claro, contestações ao primado do Direito Comunitário por parte dos respectivos órgãos jurisdicionais. De um modo geral, porém, atualmente a doutrina do primado do Direito Comunitário desenvolvida, como visto, pelo Tribunal, tem sido por eles amplamente aceita.

Vale enfatizar, por fim, que o Tribunal não tem se utilizado de uma retórica vazia quando afirma ser o primado do Direito Comunitário sobre o Direito Interno dos Estados-Membros uma das características essenciais da ordem jurídica da Comunidade. A respeito comentam Weatherill e Beaumont: "It is remarkable that the constitutional provisions, legislatures and judiciary in each of the member states by their acceptance of the principle have made it a reality. This has not been brought about by coercion or threat of financial sanctions, but rather by the political and legal will to found a Community established on the principle of respect for the rule of the law. A situation where the application of Community law varies from member state to member state would be a denial of the rule of law and would make the Community untenable"

7. Conclusões.

Conforme exposto, o aspecto revolucionário desse processo de integração reside exatamente na transferência de soberania a instituições de caráter supranacional. Ora, não há nada mais comphıcado para um Estado do que, por exemplo, delegar decisões

54. Caso 106/77, Amministrazione delle Finanze..., [1978] ECR 629.

55. Apud Elizabcth Accioly, Mercosul... op. cit, p.119. 
de política econômica. Aliás, como bem reflete Rubens Ricupero, haverá sempre uma tensão dialética entre a propensão de que as economias se tornem cada vez menos nacionais e regionalizadas ou globalizadas, de um lado, e a afirmação, na tomada de decisões, da base nacional e soberana em que se fundamenta a organização política dos Estados, do outro. Por isso é que, na aplicação das regras de concorrência da Comunidade, essa tensão dialética pode ser observada com grande clareza.

Sem desmerecimento do papel desempenhado pela Comissão, pode-se afirmar, por exemplo, que o controle exercido pelo Tribunal de Justiça sobre práticas violadoras das regras de concorrência por parte dos Estados-Membros, teve, e continua tendo, crucial importância para a consolidação do processo de integração europeu. Em uma série de julgados, o Tribunal acabou por desenvolver um notável equilíbrio institucional entre o poder regulador dos Estados-Membros e as regras de concorrência da Comunidade. É impensável que esse processo de acomodação de interesses pudesse ser feito pelos Estados-Membros. ${ }^{56}$

Resta claro, pois, que o sistema jurídico de caráter supranacional com amplas competências outorgadas ao Tribunal de Justiça tem sido uma das condições fundamentais para a eficácia do projeto de integração da União Européia.

Ressalte-se, por fim, que a afirmação acima sobre a condição de eficácia do projeto de integração europeu pode não ser necessariamente válida para outros processos de integração. Dependerá sempre do modelo de integração adotado e dos objetivos a serem perseguidos.

Com a assinatura do Protocolo de Ouro Preto, em 1994, o sistema de solução de disputas do Mercosul (originado do Protocolo de Brasília, em 1991), por exemplo, teve sua natureza predominantemente diplomática reforçada. Esse sistema de solução de disputas foi dividido claramente em duas categorias, e, como expõe Luiz Olavo Baptista, "cada uma destas em fases das quais apenas a última é a da solução arbitral", a qual é implementada pela instalação de um Tribunal Arbitral ad hoc ${ }^{57} \mathrm{O}$ Mercosul, dessa forma, segundo o autor, ganhou nítidos contornos de um modelo de integração cooperativo e consensual, abandonando "a rota da supranacionalidade dos organismos do novel mercado comum" 58

Mais recentemente, com a celebração do Protocolo de Olivos (2002), os Estados-Membros do Mercosul resolveram efetuar "modificações especificas no sistema de solução de controvérsias de maneira a consolidar a segurança juridica no âmbito

56. A respeito da importância do controle pelo Tribunal de Justiça da aplicação das regras de concorrência na Comunidade, ver Umberto Celli Junior, Regras de Concorrência no Direito Internacional Moderno, Porto Alegre, Livraria do Advogado Editora, 1999.

57. Cf. Luiz Olavo Baptista, O Mercosul suas instituições e Ordenamento Juridico, Sào Paulo, LTr, 1998, p.159.

58. Cf. Luiz Olavo Baptista, "As instituições do MERCOSUL: comparaçōes c prospectiva", in $O$ Mercosul em movimento (Série Integração Latino-Americana), Deisy de Freitas Lima Ventura, org., Porto Alcgre, Livraria do Advogado Editora, 1995, pp. 55/70. 
do Mercosul" Inspirados no mecanismo de solução de controvérsias da OMC, os Estados-Membros criaram um Tribunal Permanente, o qual poderá ser acionado diretamente, isto é, sem passar pelo Tribunal $A d H o c$, ou como instância de revisão dos laudos emitidos pelo Tribunal $A d \mathrm{Hoc}$. Na forma do art. 26 do Protocolo de Olivos, os "laudos do Tribunal Permanente de Revisão são inapeláveis, obrigatórios para os Estados partes na controvérsia a partir de sua notificação e terão, com relação a eles, força de coisa julgada"

Trata-se de uma inovação importante que, nos limites traçados pelo modelo de integração adotado e em face dos objetivos a serem perseguidos, poderá, sem dúvida, contribuir com o avanço e consolidação do Mercosul.

São Paulo, junho de 2002. 